\title{
The prevalence of painful incidents among young recreational gymnasts
}

\author{
Chrystal Coates BSc(Hons), C Meghan McMurtry BA(Hons), Patricia Lingley-Pottie BNRN CCRC, \\ Patrick J McGrath OC PhD FRSC
}

C Coates, CM McMurtry, P Lingley-Pottie, PJ McGrath. The prevalence of painful incidents among young recreational gymnasts. Pain Res Manage 2010;15(3):179-184.

BACKGROUND: Although children experience pain during their daily life, research has generally focused on medical pain. Sport-related pain has not been widely studied in children and research has not examined the occurrence of painful incidents in gymnastics. The prevalence of painful incidents among children in recreational gymnastics classes and accompanying coach responses were recorded.

METHODS: Sixty-one children between five and 10 years of age were observed at a gymnastics club. A checklist was used to record painful incidents as well as coach and child responses.

RESULTS: The rate of painful incidents was 0.17 per child per hour observed. The floor apparatus was the most common site of incidents, while bumping into equipment was the most common incident. Based on observer ratings, most incidents were mild to moderate in severity and, on average, the child's reaction to these mild to moderate incidents lasted for $8.5 \mathrm{~s}$. Forty per cent of the children had a mild to moderate painful experience. Coaches reacted to more than $60 \%$ of the painful incidents, usually asking how the child was and what had happened. A significant difference was found between the mean severity ratings of painful incidents that were followed by coach response and incidents followed by no response.

CONCLUSION: Most children who attend recreational gymnastics classes will likely experience at least one mild to moderate painful experience for every $6 \mathrm{~h}$ of class. Coaches are more inclined to react to a painful incident than not. Moreover, a difference was found that suggests coaches responded to more painful incidents.

Key Words: Coaches' responses; Gymnastics; Pediatric pain; Recreational sport

$\mathrm{T}$ he understanding of pain develops during childhood when the most common painful experiences children have are the minor bumps and scrapes they encounter during their normal daily routines $(1,2)$. Studies conducted on everyday pain in daycares have indicated that children experience a painful incident approximately once every $3 \mathrm{~h}$ during active play $(1,2)$. Sixty per cent of these incidents were self imposed, while $40 \%$ were linked to the deliberate actions of other children $(1,2)$. Even at this young age, the responses of adults differed by sex of the child; following a painful incident, girls received more

\section{La prévalence d'incidents douloureux chez les jeunes gymnastes récréatifs}

HISTORIQUE : Même si les enfants ressentent des douleurs dans leur vie quotidienne, les recherches portent généralement sur les douleurs d'importance médicale. Les douleurs liées au sport n'ont pas fait l'objet d'études généralisées chez les enfants, et les recherches n'ont pas abordé l'occurrence d'incidents douloureux en gymnastique. Les chercheurs ont saisi la prévalence d'incidents douloureux chez les enfants qui suivent des cours de gymnastique et les réponses des entraîneurs accompagnateurs.

MÉTHODOLOGIE : Les chercheurs ont observé 61 enfants de cinq à dix ans à un club de gymnastique. Ils ont utilisé une liste de vérification pour enregistrer les incidents douloureux ainsi que les réponses des entraîneurs et des enfants.

RÉSULTATS : Le taux d'incidents douloureux observé s'élevait à 0,17 par enfant à l'heure. Les appareils au sol étaient le lieu d'incidents le plus courant, tandis que se cogner dans du matériel constituait le principal incident. D'après les évaluations des observateurs, la plupart des incidents étaient de gravité légère à modérée et, en moyenne, la réaction de l'enfant à ces incidents durait 8,5 secondes. Quarante pour cent des enfants ont subi une expérience douloureuse légère à modérée. Les entraîneurs ont réagi à plus de $60 \%$ des incidents douloureux, demandant généralement comment était l'enfant et ce qui s'était passé. Les chercheurs ont constaté une différence significative entre les taux de gravité moyens des incidents douloureux qui ont suscité la réponse d'un entraîneur et les incidents qui n'en ont pas suscité.

CONCLUSION : La plupart des enfants qui suivaient des cours de gymnastique récréative subiront probablement au moins une expérience douloureuse légère à modérée par tranche de six heures de cours. Les entraîneurs sont plus enclins à réagir à un incident douloureux qu'à ne pas y réagir. De plus, les chercheurs ont constaté une différence selon laquelle les entraîneurs réagiraient aux incidents les plus douloureux.

physical comfort from the adults than boys and also vocalized more intensely $(1,2)$.

Although children experience pain during their daily life, research has generally focused on medical pain. Medical pain includes the pain encountered during medical procedures, such as immunizations, as well as pain encountered by children after injury or disease that requires assistance from health care professionals. Within the context of painful medical procedures, research has demonstrated that the behaviour of adults can influence the way children react to pain. For example, studies 
$(3,4)$ have shown that common adult behaviours, such as apologies, criticism, giving control to the child, reassurance and distraction, are related to the child's level of pain and distress during painful procedures, such as lumbar punctures, bone marrow aspirations and immunizations. Specifically, it was found that child distress was positively correlated with adult reassurance, apology and empathy, whereas nonprocedural talk (verbal distraction), humour and commands to engage in a coping strategy were associated with child coping $(3,4)$. Adultchild interactions during pediatric procedural pain have been frequently studied $(3,5-7)$, but little is known about these interactions in response to pediatric pain sustained during common activities such as recreational sports.

The everyday pain that children experience is far more common than medical pain. Little is known about the prevalence of pain in gymnastics and no research has examined this issue in recreational gymnastics. Gymnastics is a popular children's sport that presents numerous opportunities for painful experiences and has one of the highest injury rates in popular children's sports (8). The most common types of pain that gymnasts sustain while training are associated with the wrists, hands, spine, knees and ankles (9), which can result in persistent pain following practice. Often we only know about significant painful incidents that result in a prolonged duration of discomfort, but little is known about painful incidents of short duration that occur during gymnastics classes.

Research by Nemeth et al (10) showed that there were age differences in competitive gymnasts' understanding of pain, their use of pain descriptors and recognition of pain from exertion. Due to limited research in this area, the frequency of painful incidents experienced by young gymnasts is unclear. Moreover, the severity of the experiences and the reaction of the gymnastic coach to the painful incidents sustained by the gymnast are unknown. Given the influence that adult-child interactions have on a child's pain experience during medical procedures, there is reason to expect that a coach's response to a painful event sustained during class activities may have an impact on the child's pain experience.

Although the work by Nemeth et al (10) provided interesting data on competitive gymnasts, the majority of children participating in gymnastics are recreational rather than competitive athletes. The present study was developed to determine the frequency, intensity and duration of painful incidents among five- to 12-year-old children during recreational gymnastics classes, and to explore coach reactions to the painful incidents.

\section{METHODS}

\section{Participants}

The present study has an observational study design. Participants were pediatric members of a recreational gymnastics club located in Dartmouth, Nova Scotia, who were attending beginner classes or summer gymnastics camp; their coaches were also included. Regular gymnastics classes were observed for six weeks, followed by a week of recreational summer day camp. The information and informed consent forms were sent home with every child eligible for the study. For children who were not present at the time the forms were distributed, the parents were approached at the club. All children were given the opportunity to participate, with the following exclusion criteria: any child outside the age group of five to 12 years and above a beginner skill level of gymnastics; any child enrolled in a beginner gymnastics class in which the coach or apprentice did not consent to participate in the study; and any child who did not have an authorization form signed by their parents. The Research Ethics Board of the IWK Health Centre (Halifax, Nova Scotia) approved the present study.

Before beginning observation, written informed consent was obtained from coaches and verbal assent was obtained from the children, with written authorization from their parents. Sixty-one children (48 girls and 13 boys) ranging in age from five to 10 years (mean $[ \pm \mathrm{SD}]$ age $7.2 \pm 1.3$ years) participated. One male and 10 female coaches (mean age $20.6 \pm 8.2$ years) who taught the classes and the summer camp were included in the present study.

\section{Observational checklist}

Before undertaking any observations, a checklist was developed for a child experiencing a physically painful incident while participating in a recreational gymnastics class (Appendix A). This checklist was developed based on research by Fearon et al (1) and von Baeyer et al (2). The checklist was designed to record information describing the physically painful incident and the behaviours of coaches and children following the incident.

Observers were trained to use the checklist in a one-on-one session with the first author. There were six observers: five women and one man. Four of the observers were undergraduate students and two were graduate students. Observers used the checklist to record the type of painful incident the child sustained, the observational rating of the severity and duration of the incident, the body part affected, and the behavioural responses of both the child and the coach. Demographic information on both the child and the coach (eg, age and sex) were obtained by an observer at the time of consent.

Duration of the incident was operationalized as the time from the beginning of the incident until normal activity was resumed. Thus, the duration included both the painful stimulus (eg, bumping a knee) as well as the child's and coach's behavioural responses. Based on the observed responses of the child, the perceived physical severity of the incident was rated by observers on a scale of 1 to 10 , with 1 indicating a mild incident and 10 indicating a very severe incident. The child response(s) were coded into nine categories: crying; a pain face; reporting the incident to the coach; running to the parents; screaming; holding or touching the affected area; hitting or pushing others; ignoring the incident; or 'other'. More than one category could be assigned to fully capture the child's responses. The coach's behavioural response to the observed child's painful incident was recorded, not using a priori categories, but in a descriptive manner to allow for exploratory analysis. In addition, the type of event equipment (balance beam, vault, floor apparatus, uneven bars, trampoline or rings) on which the incident occurred was recorded.

\section{Procedure}

After obtaining consent and assent, participants were observed during their regular gymnastics class or summer camp 
program. Participants were asked to follow their ordinary routines and activities planned for their class or day camp. A typical gymnastics class would contain between one and eight children per coach. However, researchers observed a maximum of four children per class at once. Some children in the regular gymnastics program were observed for more than one class and, therefore, could have been observed for $1 \mathrm{~h}$ to $3 \mathrm{~h}$. Because the children involved in summer camp participated in gymnastics for $3.5 \mathrm{~h}$ each day, they were observed for lengths of time between $3.5 \mathrm{~h}$ and $14 \mathrm{~h}$ over a maximum of four days.

The gymnastics club's event equipment included six balance beams, one vault, one floor apparatus, two sets of uneven bars, two trampolines and one set of rings. During each gymnastics class or camp, the gymnasts participated in all events for approximately equal periods of time. When possible, each apparatus was typically set up in a circuit format in which each child was able to continuously practise his or her gymnastics skills. Certain events (vault, uneven bars, trampoline and rings) allowed only one child at a time to practise his or her gymnastics skills. In contrast, two to three children could practise on the same balance beam at once. On the floor apparatus, the setup was such that only one child would be practising each gymnastics skill at any given time.

At all times, two observers independently watched the children to allow for inter-rater reliability calculations. The observers recorded any incident of pain, its apparent cause and the subsequent coach-gymnast interaction. They observed at a distance of approximately $2 \mathrm{~m}$ and ensured that all activities were in front of them and could be easily viewed without disturbing the participants. Observers interacted as little as possible with the participants and observed all activities. Because the participants were completing circuits, there may have been times when a child was waiting in line rather than performing an activity. Thus, observers simply scanned all the participants in a class rather than fixating on any particular individual. Observers followed the groups of participants as they moved from event to event.

\section{Data analysis}

Frequency analysis was used to determine the type, duration and perceived severity of each painful incident the children experienced, as well as the event equipment associated with the incident. Means were used to describe the number of painful incidents experienced by age. After data collection, codes were created for the coaches' responses based on the data. Content and frequency analysis were used to describe child and coach responses to the painful incidents. Post hoc, independent $t$ tests were used to explore any differences between coach response and no response. All statistics were calculated using SPSS 14.0 (SPSS Inc, USA).

\section{RESULTS}

Inter-rater reliability was calculated via per cent agreement as the amount of agreement between observers for each category on the checklist. The purpose of the present study was not to discover meaningful differences between participants but rather to describe the painful incidents observed during a recreational gymnastics class. Therefore, if observers recorded the severity of the painful incident within \pm 1 rating of each other,
TABLE 1

Painful incidents experienced in each age group over
262 total child hours of observation

Age group,

\begin{tabular}{lccc} 
years & Children in age group, $\mathbf{n}$ & Painful incidents, $\mathbf{n}$ & Rate $^{*}$ \\
\hline 5 & 5 & 1 & 0.20 \\
6 & 15 & 12 & 0.80 \\
7 & 20 & 18 & 0.90 \\
8 & 12 & 2 & 0.17 \\
9 & 6 & 10 & 1.67 \\
10 & 3 & 2 & 0.67 \\
\hline
\end{tabular}

*Number of incidents per child in each age group

then agreement was considered to be achieved. Similarly, agreement was achieved if the observers' scores for the duration of the painful incident were within \pm 5 s. Observers had $91 \%$ to $98 \%$ agreement in each category on the checklist (eg, type of painful incident, severity, duration, and coach and child responses to the painful incident). In cases of disagreement between observers, the mean rating of the two observers' scores was used for analysis. If there was disagreement about the child and coach responses, all recorded responses were used in the analysis.

One child participated in both the classes and the camp; therefore, the camp data were removed from analyses. In addition, data collected on a child with a significant mental health disorder who demonstrated extreme behavioural reactions to four painful incidents were deleted. This yielded a total of 61 participants.

\section{Frequency of painful incidents}

All participants reported previous experience with gymnastics, except for one child in the camp program. This child did not experience any painful incidents. Overall, painful incidents occurred at a rate of 0.17 incidents per child per hour observed (45 incidents in 262 child hours of observation) and were experienced by 24 different children (39\%). No painful incidents were observed for 37 children (61\%). Girls experienced an average of 0.18 painful incidents per child hour ( 35 incidents for 48 girls in 194 female child hours). Boys experienced an average of 0.15 painful incidents per child hour (10 incidents for 13 boys in 68 male child hours). No significant difference in the frequency of painful incidents was found between younger (five- to seven-year-olds) and older (eight- to 10-year-olds) children, $(t[59]=0.177, \mathrm{P}=0.860)$. Table 1 contains the frequency of incidents in each age group.

Frequency analysis showed that the most common painful incidents $(24.4 \%$; 11 incidents) occurred as a result of bumping into equipment, while $15.6 \%$ (seven incidents) occurred from falling off equipment and stubbing toes (Table 2). One incident resulting in a laceration required first aid intervention (ie, application of an adhesive bandage). Participants experienced the greatest number of painful incidents on the floor apparatus (21/45) followed by the balance beam (7/45), uneven bars (6/45), vault (5/45), trampoline (5/45) and rings $(1 / 45)$.

\section{Duration of painful incidents}

The majority of the observed painful incidents lasted for $10 \mathrm{~s}$ or less $(75.6 \%$; 34 incidents), while $13.3 \%$ of painful incidents 
TABLE 2

Type and frequency of painful incidents experienced by the children over 262 total child hours of observation

\begin{tabular}{lc}
\hline Type of incident & Frequency, $\mathbf{n}(\%)$ \\
\hline Bumped into equipment & $11(24.4)$ \\
Fell off equipment & $7(15.6)$ \\
Stubbed toe & $7(15.6)$ \\
Bumped, collided with another & $5(11.1)$ \\
Rolled, twisted joints & $4(8.9)$ \\
Scrapes, cuts or abrasions & $4(8.9)$ \\
Tripped over equipment & $3(6.7)$ \\
Sore hands & $2(4.4)$ \\
Cramps & $1(2.2)$ \\
Pushed by another & $1(2.2)$ \\
Total & $45(100)$ \\
\hline
\end{tabular}

TABLE 3

Type and frequency of the children's responses to the painful incidents occurring over 262 total child hours of observation

\begin{tabular}{lc}
\hline Child response type & Frequency, $\mathbf{n}(\%)$ \\
\hline Verbal exclamation & $28(26.7)$ \\
Holding, touching of affected area & $25(23.8)$ \\
Pain face & $24(22.9)$ \\
Reporting incident to coach & $8(7.6)$ \\
Rubbing of affected area & $6(5.7)$ \\
Resting & $5(4.8)$ \\
Laughing & $3(2.8)$ \\
Shaking of affected area & $3(2.8)$ \\
Crying & $2(1.9)$ \\
Screaming & $1(0.9)$ \\
\hline
\end{tabular}

(six incidents) lasted from $11 \mathrm{~s}$ to $30 \mathrm{~s}$, and only $11.1 \%$ of the incidents (five incidents) lasted for longer than $30 \mathrm{~s}$.

Severity of painful incidents

Observers did not rate any incidents of perceived severity above a moderate rating of 4 (ie, the overall range was 1 to 4 of 10). The majority of painful incidents were mild, with severity ratings of 1 or 2 ( $86.7 \%$; 39 incidents), while the remainder had severity ratings of 3 or 4 (13.3\%; six incidents).

Child and coach reactions to the painful incidents

The majority of the young gymnasts' reactions to the painful incidents included verbal exclamations, holding or touching the affected area, or facial pain responses. Table 3 shows the type and frequency of the children's responses to the painful incidents.

Post hoc independent $t$ tests were conducted to explore possible mean differences in severity and duration of incidents followed by coach response versus no response. Significant differences were found when comparing coach response versus no response to the severity of the painful incident $(t[43]=2.21$, $\mathrm{P}=0.03$ ); on average, incidents that coaches responded to had a higher severity rating than incidents that were followed by no response. However, there were no significant differences found between coach response and no response for the duration of the painful incident $(t[43]=0.82, \mathrm{P}=0.42)$ (Table 4).

Content analysis revealed common responses made by coaches to the painful incidents. Table 5 shows the type and
TABLE 4

Comparison between coach response and no response to the painful incident and the severity (0 to 10) and duration of the painful incident

\begin{tabular}{lcc}
\hline & Response $(\mathbf{n}=25)$ & No response $(\mathbf{n}=\mathbf{2 0})$ \\
\hline Severity & $2.02 \pm 0.72$ & $1.55 \pm 0.63$ \\
Duration, s & $18.42 \pm 35.02$ & $11.55 \pm 14.88$ \\
\hline
\end{tabular}

Data presented as mean $\pm S D$. Total sample size $n=45$; mean severity $1.81 \pm 0.74$; mean duration $15.37 \pm 27.99 \mathrm{~s}$

TABLE 5

Type and frequency of the coach response to the painful incidents occurring in $\mathbf{2 6 2}$ total child hours of observation

\begin{tabular}{lc}
\hline Coach response type & Frequency, n (\%) \\
\hline No response & $19(36.5)$ \\
Queried whether child was all right & $13(25)$ \\
Queried what happened & $6(11.6)$ \\
Demonstrated or instructed proper skill technique & $5(9.6)$ \\
Listened to child & $5(9.6)$ \\
Assisted or comforted child & $4(7.7)$ \\
\hline
\end{tabular}

frequency of coach responses. The observed responses included no response at all, inquiry about whether the child was all right, inquiry about what happened, and/or instruction or demonstration of the proper technique for the skill. Coaches also listened to the children retell their versions of the painful incidents and gave assistance or comfort.

\section{DISCUSSION}

Gymnastics is an active sport during which children may sustain injuries resulting in painful experiences. The present study described the point prevalence of painful incidents in children while participating in recreational gymnastics classes and the coaches' responses to these painful incidents. In these beginner gymnastics classes, $39 \%$ of the children experienced a painful incident. Thus, $61 \%$ of participants did not experience a painful incident. The prevalence of painful incidents observed in the present study suggests that a child attending a recreational gymnastics class has the likelihood of sustaining at least one mild to moderate painful event per $6 \mathrm{~h}$ of class activity. Thus, in a typical beginner gymnastics class, most children do not experience a painful incident.

The highest number of painful incidents observed resulted from children bumping into equipment, perhaps because they were distracted. Painful incidents most commonly occurred on the floor apparatus $(\mathrm{a} 40 \mathrm{ft} \times 40 \mathrm{ft}$ square foam mat on top of springs attached to plywood), balance beam and uneven bars. The finding that most painful incidents occurred on the floor apparatus was interesting because the trampoline appears to be a more likely apparatus for painful incidents (11). The number of painful incidents on the floor apparatus may have been artificially increased because there were a greater number of children on the floor apparatus at any one time compared with other event equipment. Anecdotal observations revealed that coach procedures for managing the children's behaviour during trampoline activities were stricter than during floor apparatus activities. Increased coach control may explain the lower incident rate associated with the trampoline. Perhaps enhanced coach supervision and direction during other gymnastic activities would decrease the prevalence of painful incidents. 
Children typically responded to a painful incident with a verbal exclamation, holding or touching the affected area, or a pain face. Although one of the most common coach reactions to the child's painful incident was no response (36.5\%), this did not seem to hinder the flow of the class. It is difficult to know whether these incidents were actually unnoticed or whether the coaches were actively ignoring the children. The coaches' responses could be considered entirely appropriate because the children typically encountered only minor incidents of pain (observer-rated severity of 4 or less of 10).

When coaches did respond to the child's pain event, it was often to query whether the child was all right. Coaches who reacted to the painful incidents seemed to respond to the child with patience. The patience the coach demonstrated was usually successful in encouraging the child to continue his or her participation in the class. Also, instruction or demonstration by the coach of the proper skill technique may have helped decrease the occurrence of painful incidents when the child attempted the skill a second time.

The comparison of mean severity ratings between coach response versus no response shows that coaches respond differently depending on the severity of the child's pain experience. Coaches were more likely to respond to painful incidents of higher severity than lower severity. However, the direction of causation is unclear. It is possible that a coach response to a child's painful incident may influence a child's reaction to pain as has been found in the medical literature (12).

Further research is needed to explore whether the results of the present study may be replicated in a study designed to evaluate self-report of pain, and also whether the pain persists after the class. Additionally, it would be valuable to find out whether a parent would perceive this prevalence as a meaningful concern. Future research could also investigate the prevalence of painful incidents and adult/coach responses in other recreational ball sports such as baseball, soccer, basketball, football and volleyball. A future study designed to record the child's self-reported pain experience while controlling for coach response to painful events would provide further insight into any influence that coach responses may have on the child's pain experience. Interactions between adults and athletes have not been studied within the context of sport-related pain.

The findings of a study by Chambers et al (12) indicated that maternal behaviour directly influenced girls' subjective reports of pain but not their pain affect, facial activity or heart rate. Boys were not affected by maternal behaviour. Thus, a study examining the impact of coach behaviour on a child's self-reported pain experience that explored sex differences would help to elucidate how children cope with pain incidents during recreational gymnastic activities.

A future study exploring the understanding of pain among nonathletes, and recreational and competitive gymnasts, could help coaches succeed in accurately assessing their athletes' level of pain tolerance. Results could be compared with the study conducted by Nemeth et al (10), which explored the understanding of pain by competitive athletes. These researchers investigated competitive child gymnasts' understanding of pain by analyzing their knowledge of different types of sport-related pain, such as pain from conditioning versus acute pain versus chronic pain, their use of pain descriptors, and their expectations for adult help following painful incidents. The study found that gymnasts reacted differently to various types of pain, and that there were age differences in the understanding and use of descriptors for pain. In contrast to younger gymnasts, older gymnasts could distinguish between pain that was too severe to continue training from pain that they would be willing to endure, especially when it was going to help with physical gain (eg, the pain experienced during conditioning). Therefore, in the future, it would be interesting to use self-reports from the gymnasts and coaches to investigate the experience of painful incidents in gymnastics classes.

One limitation of the present study was that the severity and duration ratings of the children's pain experience were observational and limited to class time. Without knowing the children's self-reported experience, we do not know whether the observers' perceived severity and duration ratings were commensurate with the children's actual experience. A second limitation was that the exploratory study design did not allow for follow-up with participants to discuss their pain experience after the gymnastics class. The objective of the present initial study was to investigate the prevalence of painful incidents that occurred during the class. However, future research could address these issues.

The present study was observational in nature and demonstrated that participating in recreational gymnastics classes does expose children to the possibility of experiencing a mild to moderately painful incident. The results of the present study also suggest that a positive, constructive coach response to a painful event may provide encouragement to the child. With coach supervision, instruction and encouragement, children can potentially learn basic motor skills and coordination, and gain confidence during gymnastic activities, which may lead to decreased future incidents.

The present study provides evidence that gymnastics is not as dangerous a sport as some believe it to be (8) and young children can participate in the sport without experiencing serious pain. Specifically, the overall rate of painful incidents in the present study was low. Pain from conditioning and from acute and chronic injury may be more common at the elite, competitive levels of gymnastics, when children spend far more hours at the gymnasium, become more fatigued and practise riskier manoeuvres (10). At the recreational level, it seems unlikely that a child will encounter a severely painful incident, suggesting that recreational gymnastics may not be as precarious as one expects (8).

ACKNOWLEDGEMENTS: A grant to the first author from the IWK Health Centre, Dr McGrath's Canada Research Chair and a grant from Neuroscience Canada to Dr McGrath provided support for this study. These data were presented in part at the Canadian Pain Society Annual Conference (Halifax, Nova Scotia, May 2005). The authors thank the Titans Gymnastics and Trampoline Club (Dartmouth, Nova Scotia) for their support and use of the facilities for data collection. The authors also thank B Ernst, D Kempster, D Nugyen and M MacLeod for their assistance.

NOTE: This work originated from the Centre for Research in Family Health at the IWK Health Centre. 


\section{APPENDIX A}

\section{Painful Incident Chedklist}

\begin{tabular}{|c|c|}
\hline CHILD ID: & COACH OR APPRENTICE ID: \\
\hline INITIALS: & INTIALS: \\
\hline$\square$ Coach $\square$ Apprentice & \\
\hline Age of coach or apprentice: years & - \\
\hline Experience coaching: & \\
\hline Gender: $\square$ Male $\square$ Female & \\
\hline Painful Incidents for the Child & \\
\hline$\underline{\text { Event }}$ & $\underline{\text { Result }}$ \\
\hline$\square$ tripped over equipment & $\square$ broken bone(s) specify location: \\
\hline$\square$ bumped into another child & $\square$ unconscious \\
\hline$\square$ fall off equipment & $\square$ cut/abrasion specify location: \\
\hline$\square$ bump into equipment & $\square$ twisted joint specify location: \\
\hline$\square$ stubbed toe & $\square$ swelling specify location: \\
\hline$\square$ minor / major carpet burn & $\square$ other: \\
\hline$\square$ other: & \\
\hline Severity of incident: 1 (mild) 23456 & 78910 (most severe) \\
\hline Approximate duration of incident: & \\
\hline Date: & Time: \\
\hline Children's Responses to the Incidents & \\
\hline$\square$ crying & $\square$ screaming \\
\hline$\square$ pain face & $\square$ hold injury and jump around \\
\hline$\square$ reported event to coach/apprentice & $\square$ hit or push another child \\
\hline$\square$ ran directly to parents & $\square$ ignore the incident and resume activity \\
\hline$\square$ other: & - \\
\hline Coach/Apprentice Reactions (be as det & ailed as possible) \\
\hline
\end{tabular}

Notes:

\section{REFERENCES}

1. Fearon I, McGrath PJ, Achat H. 'Booboos': The study of everyday pain among young children. Pain 1996;68:55-62.

2. von Baeyer CL, Baskerville S, McGrath PJ. Everyday pain in three- to five-year-old children in day care. Pain Res Manage 1998;3:111-6.

3. Blount RL, Corbin SM, Sturges JW, Wolfe VV, Prater JM, James LD. The relationship between adults' behaviour and child coping and distress during BMA/LP procedures: A sequential analysis. Behav Ther 1989;20:585-601.

4. Manimala MR, Blount RL, Cohen LL. The effects of parental reassurance versus distraction on child distress and coping during immunizations. Child Health Care 2000;29:161-77.

5. Blount RL, Piira T, Cohen LL. Management of pediatric pain and distress due to medical procedures. In: Roberts MC, ed. Handbook of Pediatric Psychology, 3rd edn. New York: Guilford, 2003:216-33.

6. Blount RL, Sturges JW, Powers SW. Analysis of child and adult behavioral variations by phase of medical procedure. Behav Ther 1990;21:33-48.

7. Chambers CT. The role of family factors in pediatric pain. In: McGrath PJ, Finley GA, eds. Pediatric Pain: Biological and Social Context. Seattle: IASP Press, 2003:99-130.

8. Singh S, Smith GA, Fields SK, McKenzie LB. Gymnastics-related injuries to children treated in emergency departments in the United States, 1990-2005. Pediatrics 2008;12:e954-60.

9. Zetaruk MN. The young gymnast. Clin Sports Med 2000;19:757-80.

10. Nemeth RL, von Baeyer CL, Rocha EM. Young gymnasts' understanding of sport-related pain: A contribution to prevention of injury. Child Care Health Dev 2005;31:615-25.

11. Smith GA. Injuries to children in the United States related to trampolines, 1990-1995: A national epidemic. Pediatrics 1998;101:406-12.

12. Chambers CT, Craig KD, Bennett SM. The impact of maternal behaviour on children's pain experiences: An experimental analysis. J Pediatr Psychol 2002;27:293-301. 


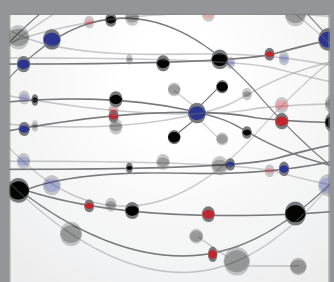

The Scientific World Journal
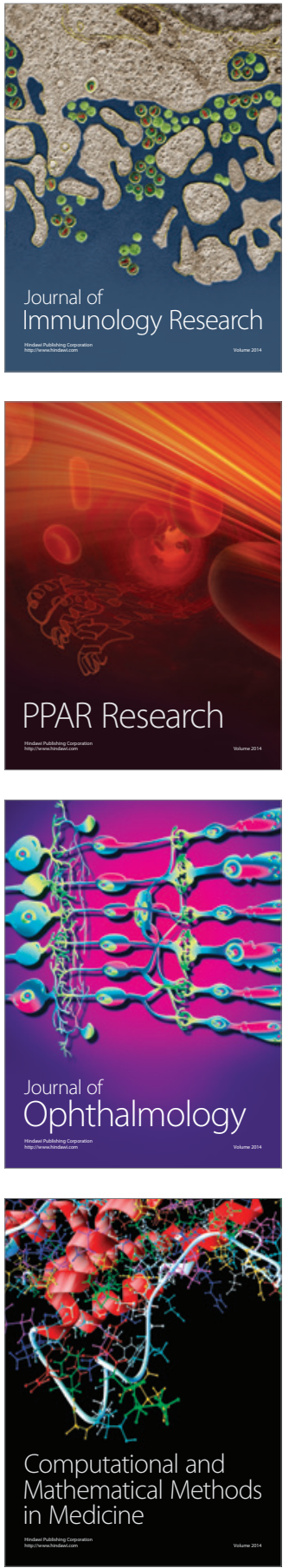

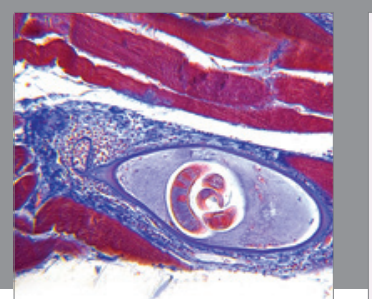

Gastroenterology Research and Practice

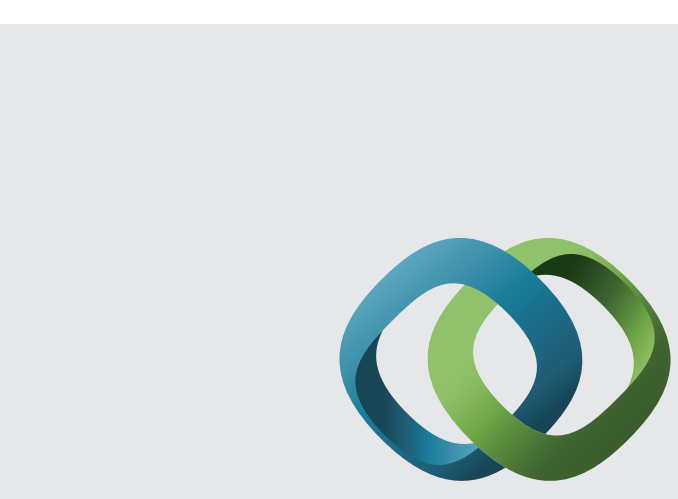

\section{Hindawi}

Submit your manuscripts at

http://www.hindawi.com
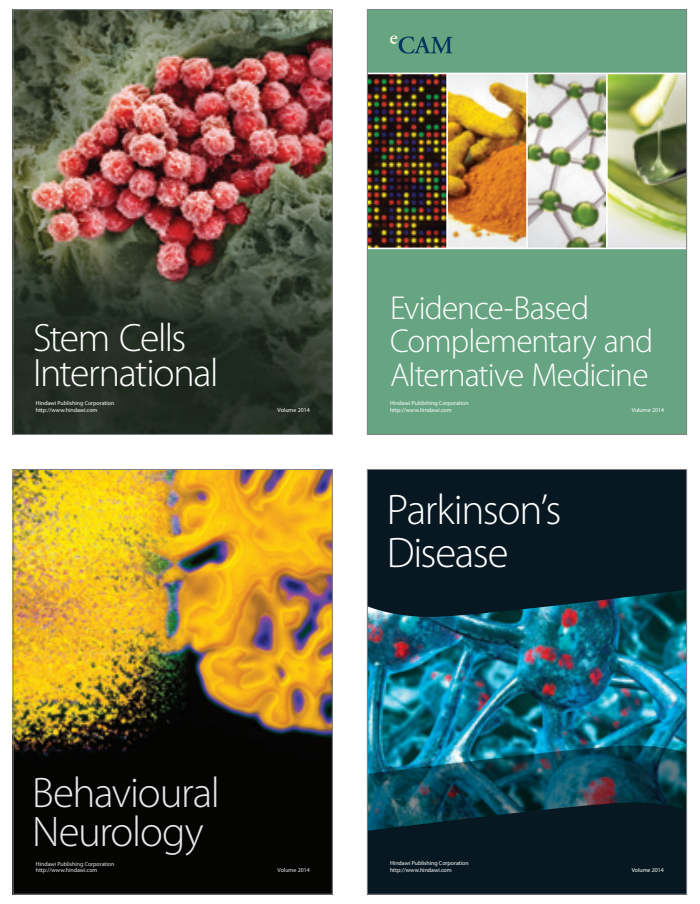
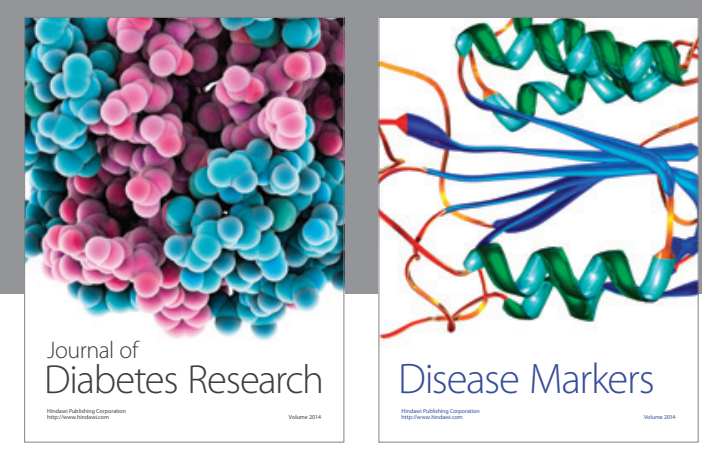

Disease Markers
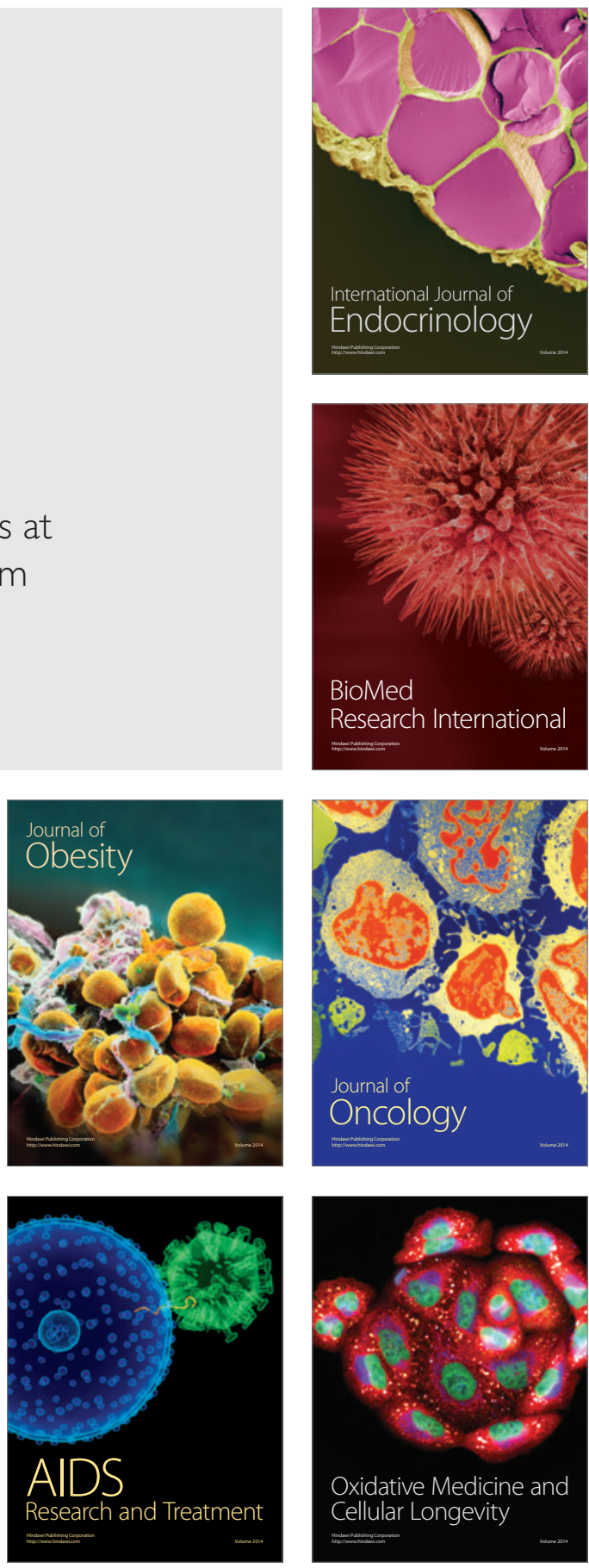